\title{
Comparative Analysis of Grid Connected Transformerless Photovoltaic Inverters for Leakage Current Minimization
}

\author{
A. Arrul Dhana Mathi* and R. Ramaprabha \\ 'Department of Electrical and Electronics Engineering, SSN college of Engineering, \\ Kalavakkam, Tamil Nadu -63110, India; ramaprabhar@ssn.edu.in
}

\begin{abstract}
Objectives: To make a comparative analysis of four transformerless topologies namely $\mathrm{H} 5$, H6, oH5 and H-Bridge Zero Voltage State Rectifier (HBZVR) in terms of leakage current and THD. Methods/Statistical Analysis: H5, H6, oH5 and HBZVR topologies have been simulated. Then these topologies are compared in terms of leakage current and THD. Based on the comparative analysis, the topology with less leakage current and THD has been chosen for photovoltaic interface. The interfacing circuit is simulated and realized as prototype to validate the results practically. Findings: It is found from the review that HBZVR topology has less leakage current and THD. This topology employs both galvanic isolation and Common Mode Voltage (CMV) clamping. It is found that the common mode voltage in HBZVR is almost eliminated. The conclusion derived from this paper may be helpful in selecting proper topology for PV interface. Application/ Improvements: Generally, in grid connected PV inverters, transformers provide galvanic isolation between the two electrical circuits, thus preventing the flow of leakage current between the stray capacitance of PV and ground. But, ransformers reduce the overall efficiency of the system, which lead to the development of transformerless PV system. Galvanic connection exists between the PV and grid in transformerless inverter, which leads to the presence of leakage current. So, to reduce leakage current, many topologies are introduced which employs either dc-decoupling or ac-decoupling to provide galvanic isolation. The HBZVR topology provides proper isolation for PV interface where the capacitance of the panel with respect to ground is large.
\end{abstract}

Keywords: Comparison, Leakage Current, Isolation, Transformerless PV Inverters, THD

\section{Introduction}

Today non-renewable energy resources are becoming more and scarcer and it leads to use of renewable energy resources as an alternative for energy production. Among the renewable energy sources Photovoltaic (PV) source is more attractive due to its abundant and free availability, long life of PV system and less maintenance. The main drawback of grid connected PV system is its high cost for initial investment and generation compared. To get back the money invested in a shorter time, the efficiency of the system, mainly the efficiency of the inverter must be improved ${ }^{1,2}$. So that after some time, the system runs with little maintenance, which means the energy is produced at almost free of cost.

The grid connected PV inverters can be of two types; one with transformer and other without transformer $\frac{3.4}{4}$. The efficiency of the overall system can be improved and the cost can be reduced in transformer-less inverters. When transformers are removed, there will be no galvanic isolation between the PV and the grid which leads to leakage current flow between the ground and stray capacitance of $\mathrm{PV}$ and the grid ${ }^{5,6}$. The presence of leakage current causes high losses and also sometimes shock when people touch the panels. The galvanic isolation in transformer-less topology can be provided by either dc- decoupling or

*Author for correspondence 
ac-decoupling. It is noted that the ac-decoupling provides low loss compared to dc-decoupling because of less number of switches in the conduction path. The leakage current in transformer-less topologies is also due to improper clamping of Common Mode Voltage (CMV). So, to fully remove the leakage current, galvanic isolation must be provided and CMV should be clamped properly. The block diagram of the overall system is shown in Figure 1.

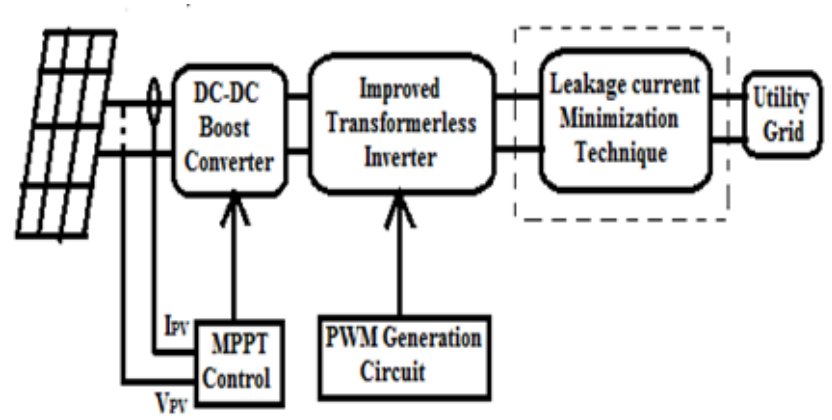

Figure 1. Block diagram of the entire system.

The transformer-less topologies like H5, H6 offers galvanic isolation by commissioning dc-decoupling or ac-decoupling to disconnect the PV and the grid. But, the common mode voltage is not maintained constant in these topologies. Hence the leakage current will not be completely eliminated in these topologies. Therefore, in topologies like oH5 and HBZVR (H-Bridge Zero Voltage state Rectifier), the CMV is clamped and the leakage current is completely eliminated $\frac{7,8}{}$.

In this paper, the above four transformer-less topologies namely $\mathrm{H} 5, \mathrm{H} 6, \mathrm{oH} 5$ and HBZVR are analyzed in terms of leakage current and Total Harmonic Distortion (THD). The comparative analysis is presented.

The forthcoming sections discuss the mathematical modelling of photovoltaic (PV) panel, condition for eliminating leakage current, operational principles of different transformer-less topology like H5, H6, oH5 and HBZVR and illustration of simulation and experimental results.

\section{Mathematical Modelling of Photovoltaic (PV) Panel}

A number of PV panels are connected in series/parallel depending upon the voltage and current requirements respectively. Figure 2 shows the equivalent circuit of PV source. The mathematical modelling of photovoltaic panel is carried out at standard test conditions of insolation of $1000 \mathrm{~W} / \mathrm{m}^{2}$ and temperature of $25^{\circ} \mathrm{C}$ with $\mathrm{V}_{\mathrm{OC}}=21.24 \mathrm{~V}$ and $\mathrm{I}_{\mathrm{SC}}=2.55 \mathrm{~A}$, where $\mathrm{V}_{\mathrm{OC}}$ is the open circuit voltage and $\mathrm{I}_{\mathrm{SC}}$ is the short circuit current ${ }^{9,10}$. Six panels are connected in series to obtain input voltage of $110 \mathrm{~V}$ for the inverter and the characteristic of the $6 \times 1$ array is shown in Figure 3 .

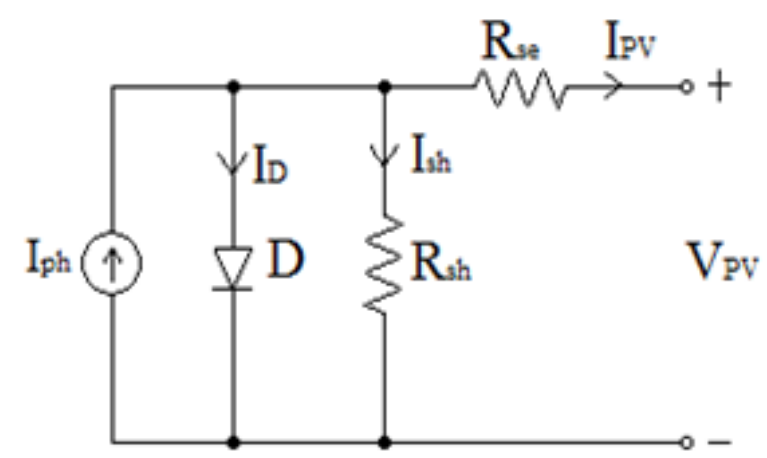

Figure 2. Electrical equivalent circuit of PV.
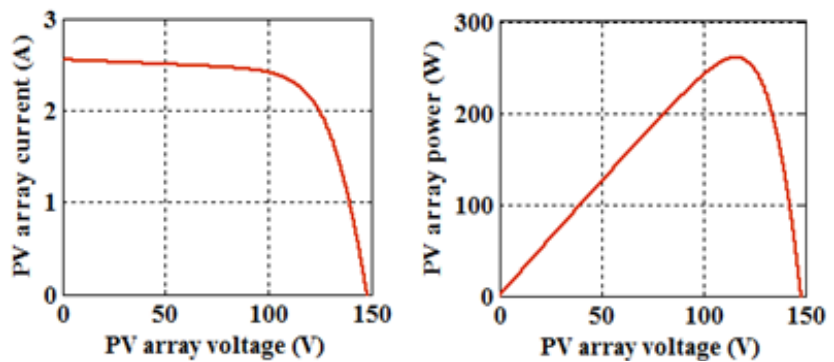

Figure 3. Characteristics of $6 \times 1 \mathrm{PV}$ array.

\section{Condition for Eliminating Leakage Current}

In transformer-less inverters, there is a galvanic connection between the PV and the grid, which forms a common mode resonant circuit $\frac{11,12}{12}$ as shown in Figure 4 , where $C_{P V}$ is the stray or parasitic capacitance, $\mathrm{L}_{1}$ and $\mathrm{L}_{2}$ are the filter inductors, $\mathrm{I}_{\mathrm{L}}$ is the leakage current and $\mathrm{V}_{\mathrm{ECM}}$ is the equivalent common mode voltage.

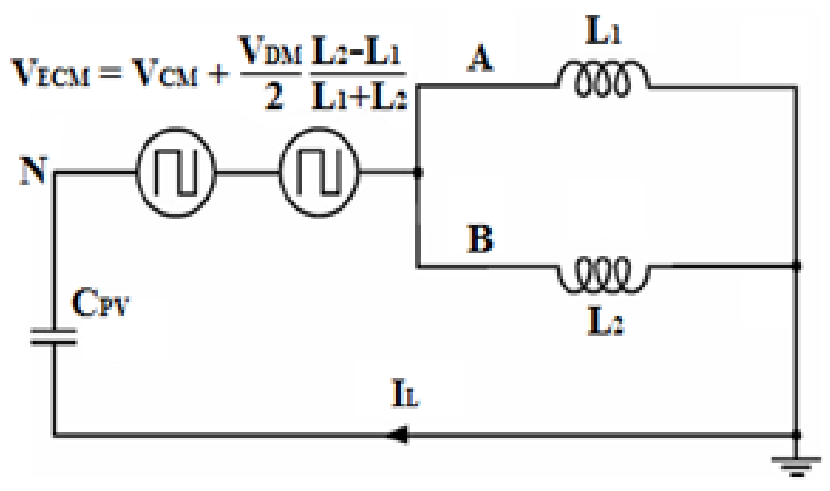

Figure 4. Resonant circuit model. 
The equivalent common mode voltage is given by equation (1).

$$
V_{E C M}=V_{\mathrm{cm}}+\frac{V_{\mathrm{DM}}}{2}\left(\frac{L_{2}-L_{1}}{L_{1}+L_{2}}\right)
$$

where, $\mathrm{V}_{\mathrm{CM}}$ is the common mode voltage and $\mathrm{V}_{\mathrm{DM}}$ is the differential mode voltage. The common mode voltage $\mathrm{V}_{\mathrm{CM}}$ and differential mode voltage $\mathrm{V}_{\mathrm{DM}}$ is given by the equation (2) and equation (3) respectively.

$$
\begin{aligned}
& V_{\mathrm{CM}}=\frac{V_{A N}+V_{B N}}{2} \\
& V_{D M}=V_{\mathrm{AB}}=V_{\mathrm{AN}}-V_{\mathrm{BN}}
\end{aligned}
$$

where, $\mathrm{V}_{\mathrm{AN}}$ and $\mathrm{V}_{\mathrm{BN}}$ are the inverter output voltages between the midpoint and neutral terminal. The condition for eliminating leakage current is to maintain the equivalent common mode voltage constant $\frac{13-15}{}$. On substituting equation (2) and (3) in equation (1), the equivalent common mode voltage is given by equation (4) as follows,

$$
V_{E C M}=\frac{V_{\mathrm{AN}}+V_{\mathrm{BN}}}{2}+\frac{V_{\mathrm{AN}}-V_{\mathrm{BN}}}{2}\left(\frac{\mathrm{L}_{2}-\mathrm{L}_{1}}{\mathrm{~L}_{1}+\mathrm{L}_{2}}\right)=\text { constant }
$$

In full bridge inverter topologies like $\mathrm{H} 5, \mathrm{H} 6, \mathrm{oH} 5$ and HBZVR topology, the filter inductors are taken same values $\left(\mathrm{L}_{1}=\mathrm{L}_{2}=\mathrm{L}_{\mathrm{f}}\right)$. The condition for eliminating leakage current in full bridge inverter is given by equation (5). It is noted that the common mode voltage must be kept constant to eliminate leakage current.

$$
V_{E C M}=V_{\mathrm{CM}}=\frac{V_{\mathrm{AN}}+V_{\mathrm{BN}}}{2}=\text { constant }
$$

\section{Operational Principles of Transformer-less Inverter Topologies - A View}

\subsection{H5 Topology}

The $\mathrm{H} 5$ topology consists of an extra switch $\mathrm{S}_{5}$ connected on the dc side of the H-bridge inverter structure as shown in Figure 5. This switch $S_{5}$ provides galvanic isolation by introducing dc decoupling to disconnect the PV and the grid. But, the common mode voltage is not clamped in this topology ${ }^{16}$. The switching sequence is shown in Figure 6. The output voltage has three levels as $+\mathrm{V}_{\mathrm{dc}}, 0$ and $-\mathrm{V}_{\mathrm{dc}}$. Switches
$\mathrm{S}_{4}$ and $\mathrm{S}_{5}$ commutate at switching frequency during the positive half cycle. Switches $\mathrm{S}_{4}$ and $\mathrm{S}_{5}$ are turned-off and the freewheeling current flows through $S_{1}$ and the anti-parallel diode of $\mathrm{S}_{3}$ during the zero voltage vectors. Switches $\mathrm{S}_{2}$ and $\mathrm{S}_{5}$ are commutates at switching frequency and the freewheeling current flows through $\mathrm{S}_{3}$ and the antiparallel diode of $S_{1}$ during the negative half cycle.

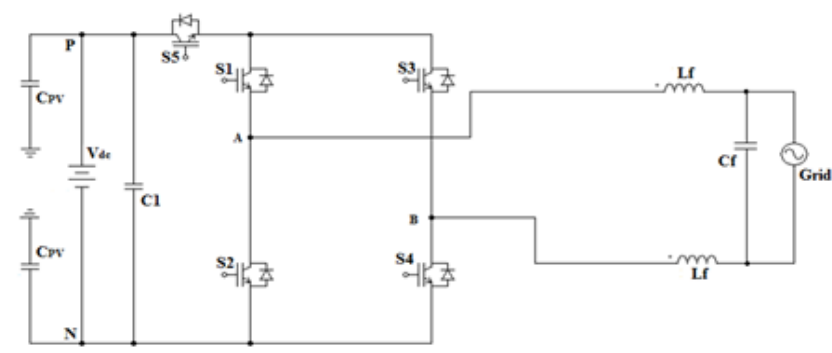

Figure 5. H5 topology converter structure.

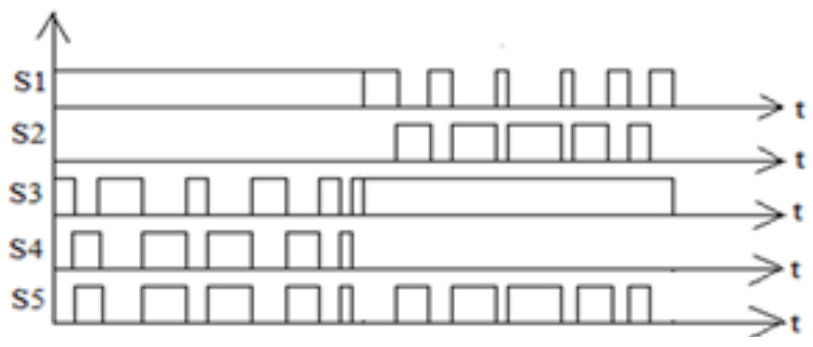

Figure 6. Switching sequence of $\mathrm{H} 5$ topology.

\subsection{H6 Topology}

The H6 topology consists of two extra switches $\mathrm{S}_{5}$ and $\mathrm{S}_{6}$ connected symmetrically on the dc side of the $\mathrm{H}$-bridge inverter structure as shown in Figure 7. The extra switches provide galvanic isolation by introducing dc decoupling to disconnect the PV and the grid $\frac{17,18}{1}$. Three level output voltages can be achieved by employing SPWM techniques and the switching sequence is shown in Figure 8. Switches $\mathrm{S}_{4}$ and $\mathrm{S}_{5}$ commutate at switching frequency and switches $\mathrm{S}_{1}$ and $\mathrm{S}_{6}$ are always $\mathrm{ON}$ during the positive half cycle. Switches $\mathrm{S}_{4}$ and $\mathrm{S}_{5}$ are turned OFF and the freewheeling

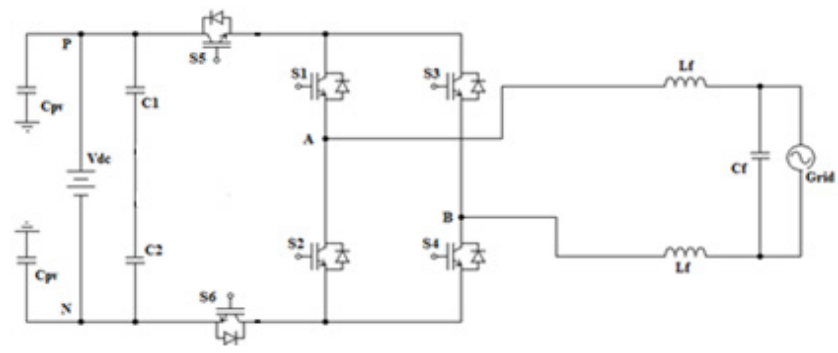

Figure 7. H6 topology converter structure. 


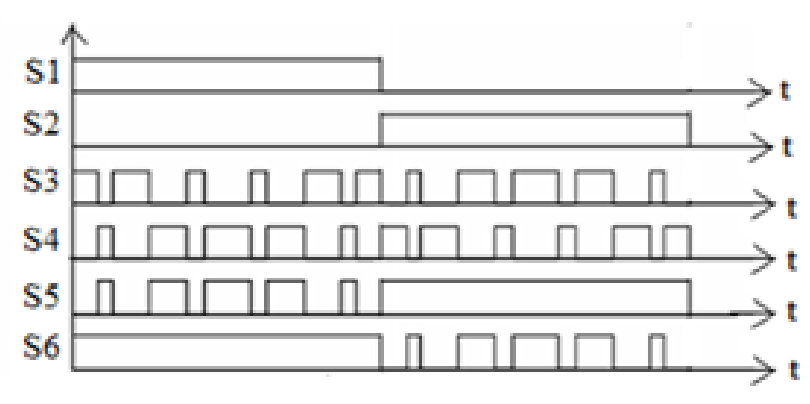

Figure 8. Switching sequence of H6 topology.

current flows through $\mathrm{S}_{1}$ and the anti-parallel diode of $\mathrm{S}_{3}$ during the zero voltage vectors. Switches $\mathrm{S}_{3}$ and $\mathrm{S}_{6}$ commutate at switching frequency and switches $S_{2}$ and $S_{5}$ are always ON during the negative half cycle. Switches $\mathrm{S}_{3}$ and $\mathrm{S}_{6}$ are turned OFF and the freewheeling current flows through $\mathrm{S}_{2}$ and the antiparallel diode of $\mathrm{S}_{4}$.

\section{3 oH5 Topology}

oH5 topology is similar to H5 topology with an extra switch $\mathrm{S}_{6}$ connected across the switch $\mathrm{S}_{5}$ as shown in Figure 9 and the switching sequence is shown in Figure 10. Unlike H5 topology, the CMV is clamped in this topology by turning $\mathrm{ON}$ switch $\mathrm{S}_{6}$ during freewheeling mode. But the input side dc-link capacitor $\mathrm{C}_{1}$ is short circuited when switch $\mathrm{S}_{5}$ and $\mathrm{S}_{6}$ are turned $\mathrm{ON}$. To overcome this problem, a small dead time should be provided between switching of switches $\mathrm{S}_{5}$ and $\mathrm{S}_{6}{ }^{19,20}$.

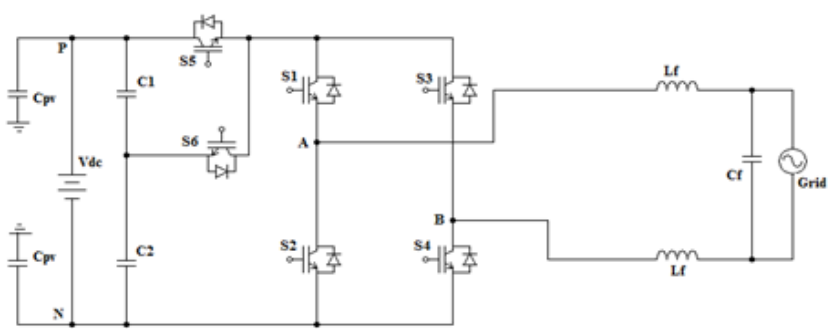

Figure 9. oH5 topology converter structure.

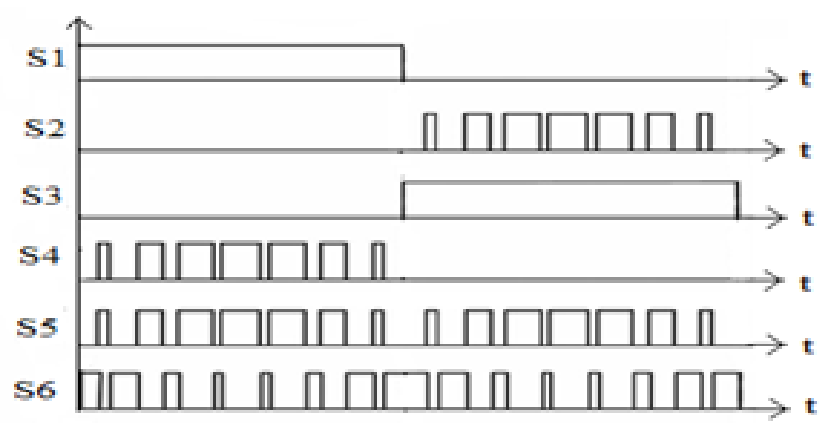

Figure 10. Switching sequence of oH5 topology.

\subsection{HBZVR Topology}

In this topology switch $\mathrm{S}_{5}$ and anti-parallel diodes $\mathrm{D}_{1}$ to $\mathrm{D}_{4}$ provides galvanic isolation to disconnect the $\mathrm{PV}$ and grid by employing ac decoupling and diodes $\mathrm{D}_{5}$ and $\mathrm{D}_{6}$ form the clamping branches as shown in Figure 11 to maintain the common mode voltage constant $t^{21-24}$. The switching pulse pattern for HBZVR topology is shown in Figure 12. Switches $\mathrm{S}_{1}$ and $\mathrm{S}_{4}$ are in ON state while all other switches are in OFF state during the positive half cycle. Switch $\mathrm{S}_{5}$ is $\mathrm{ON}$ while all other switches are OFF and the current freewheels through diodes $\mathrm{D}_{1}$ to $\mathrm{D}_{4}$ during the zero voltage vectors. Switches $\mathrm{S}_{2}$ and $\mathrm{S}_{3}$ are in ON state while all other switches are in OFF state during the negative half cycle.

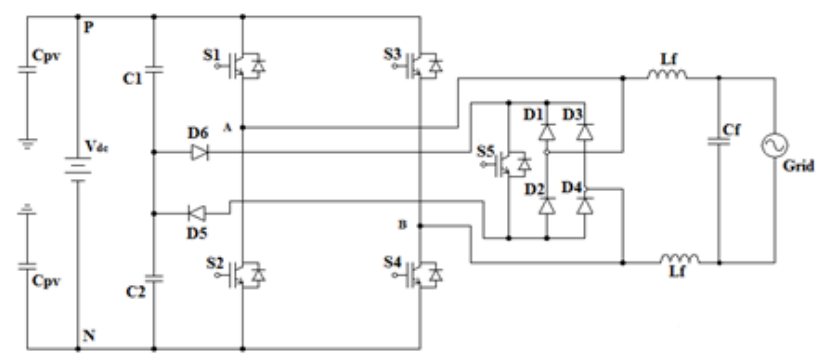

Figure 11. HBZVR topology converter structure.

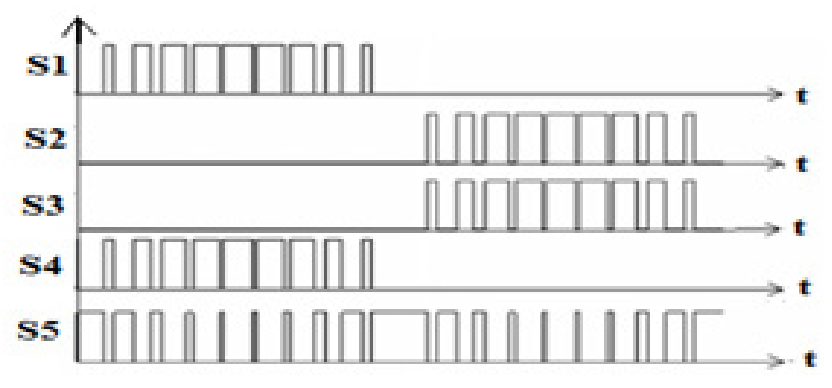

Figure 12. Switching sequence of HBZVR topology.

\section{Simulation Results}

\subsection{Leakage Current Analysis}

The transformer-less inverter topologies like H5, H6, oH5 and HBZVR topology discussed above are simulated using MatLab simulation software for input voltage of $110 \mathrm{~V}_{\mathrm{dc}}$, dc-link capacitor of $2200 \mu \mathrm{F}$, filter inductor of $3 \mathrm{mH}$, filter capacitor of $10 \mu \mathrm{F}$, switching frequency of $4 \mathrm{kHz}$ and resistive load of $30 \Omega$. The waveforms of inverter voltage before filter $\left(\mathrm{V}_{\mathrm{BF}}\right)$, inverter voltage after filter $\left(\mathrm{V}_{\mathrm{AF}}\right)$, load current $\left(\mathrm{I}_{\mathrm{LOAD}}\right)$, common mode voltage $\left(\mathrm{V}_{\mathrm{CM}}\right)$ and leakage current $\left(\mathrm{I}_{\mathrm{L}}\right)$ for H5, H6, oH5 and HBZVR topology is shown in Figures 13(a), 13(b), 13(c) and 13(d) respectively. 


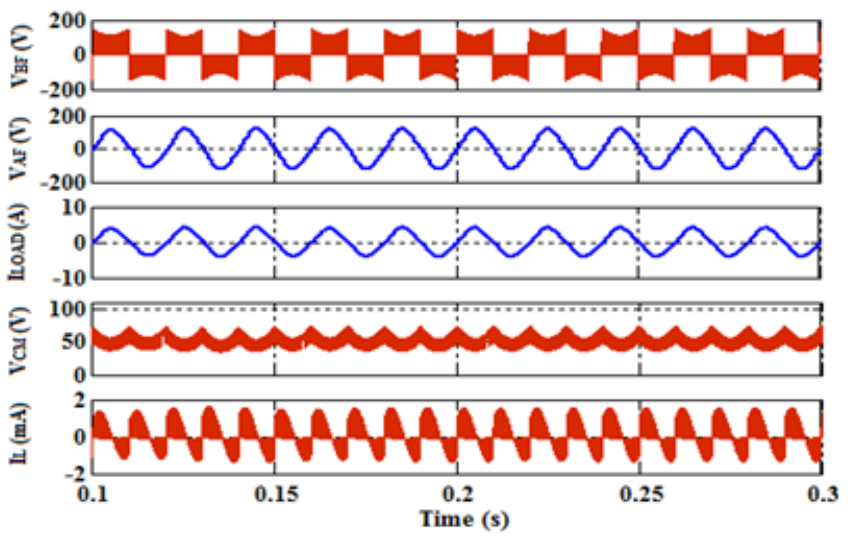

(a)

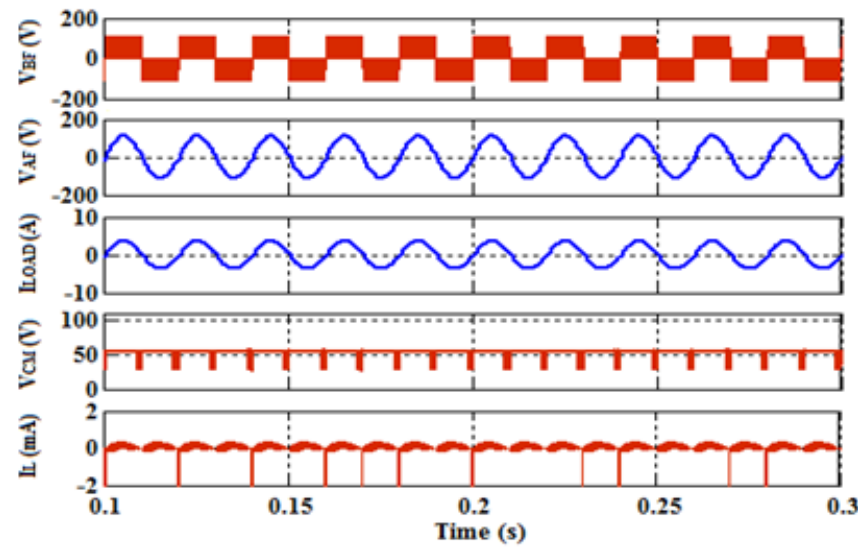

(c)

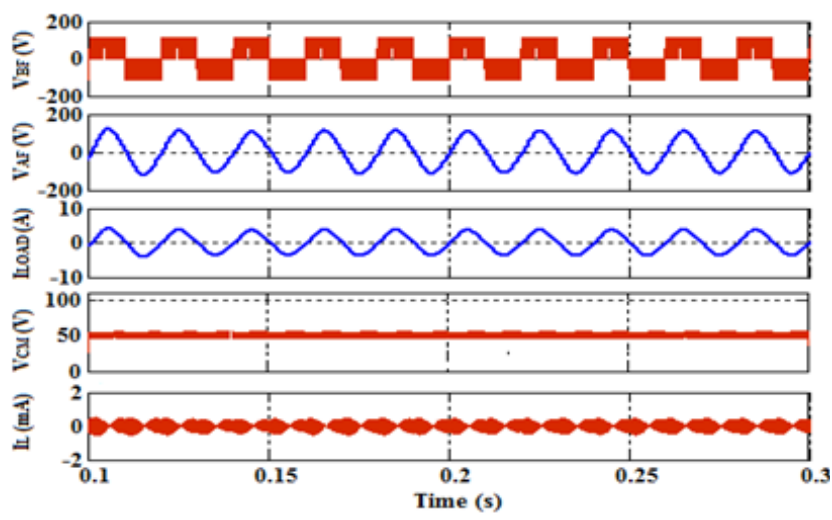

(b)

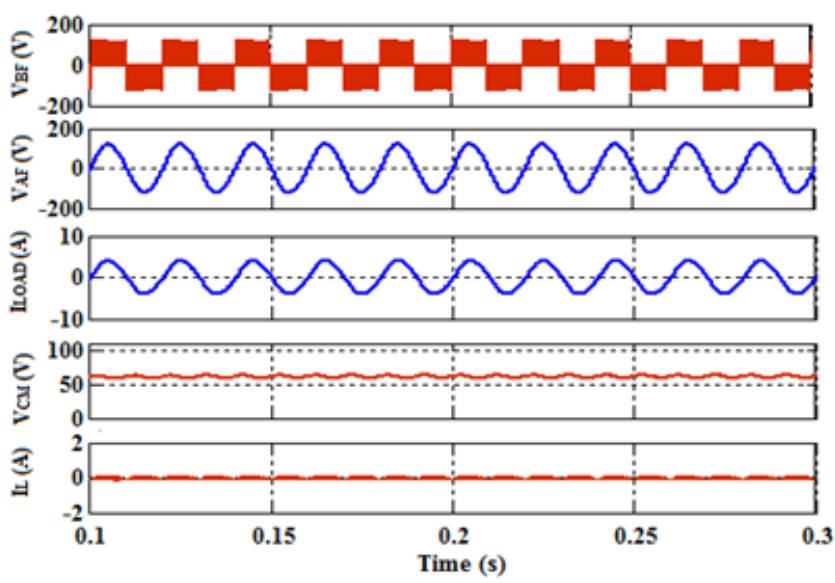

(d)

Figure 13. oH5 topology converter structure. Waveforms of inverter voltage before filter $\left(\mathrm{V}_{\mathrm{BF}}\right)$, inverter voltage after filter $\left(\mathrm{V}_{\mathrm{AF}}\right)$, load current $\left(\mathrm{I}_{\mathrm{LOAD}}\right)$, common mode voltage $\left(\mathrm{V}_{\mathrm{CM}}\right)$ and leakage current $\left(\mathrm{I}_{\mathrm{L}}\right)$ for (a) H5 topology, (b) H6 topology, (c) oH5 topology, (d) HBZVR topology.

From the waveforms, it is inferred that the leakage current is high for H5 topology compared to all other topologies. This is because the CMV is not properly clamped in this topology. The leakage current of oH5 topology is less than H5 and H6 topology because CMV clamping is provided in this topology. But, as there is a small dead time between the switches $S_{5}$ and $S_{6}$ to avoid short circuiting, the leakage current is not completely eliminated in this topology. Hence from the waveforms, it is clear that the leakage current of HBZVR topology which employs both galvanic isolation technique and CMV clamping is less compared to all other topologies.

\subsection{Total Harmonic Distortion (THD) Analysis}

The Total Harmonic Distortion (THD) of load current for different transformer-less topology is shown in Table 1; from which it is inferred that the THD (\%) for
HBZVR topology is very less compared to all the other topologies. This is because of ac-decoupling used in HBZVR topology to provide galvanic isolation unlike dc-decoupling used in other three topologies.

Table 1. THD comparison for different transformerless topologies

\begin{tabular}{|l|c|}
\hline Topology & $\begin{array}{l}\text { Total Harmonic } \\
\text { Distortion (\%) }\end{array}$ \\
\hline $\begin{array}{l}\text { H5 topology of transformer-less } \\
\text { inverter }\end{array}$ & 4.89 \\
\hline $\begin{array}{l}\text { H6 topology of transformer-less } \\
\text { inverter }\end{array}$ & 4.79 \\
\hline $\begin{array}{l}\text { oH5 topology of transformer-less } \\
\text { inverter }\end{array}$ & 4.67 \\
\hline $\begin{array}{l}\text { HBZVR topology of transformer-less } \\
\text { inverter }\end{array}$ & 1.70 \\
\hline
\end{tabular}


The THD (\%) of load current for HBZVR topology for different modulation index at switching frequency of $4 \mathrm{kHZ}$ is shown in Table 2, from which it is inferred that as the modulation index is decreased, the THD (\%) increases. The THD (\%) is less for unity modulation index. But, it is not practically possible.

Table 2. THD analysis for different modulation index at switching frequency $=4 \mathrm{kHz}$

\begin{tabular}{|c|c|}
\hline Modulation Index & Total Harmonic Distortion (\%) \\
\hline 1 & 1.70 \\
\hline 0.9 & 1.95 \\
\hline 0.8 & 2.20 \\
\hline 0.7 & 2.88 \\
\hline 0.6 & 3.16 \\
\hline
\end{tabular}

The THD (\%) of load current for HBZVR topology for different switching frequency at unity modulation index is shown in Table 3, from which it is inferred that as the switching frequency is increased, the THD (\%) decreases. A nominal selection of switching frequency and duty cycle is important to get reduced THD.

Table 3. THD analysis for different switching frequency at modulation index $=1$

\begin{tabular}{|c|c|}
\hline Switching Frequency & Total Harmonic Distortion (\%) \\
\hline 3 & 2.35 \\
\hline 4 & 1.70 \\
\hline 5 & 1.41 \\
\hline
\end{tabular}

\section{Experimental Results}

\subsection{Practical Characterization of $(6 \times 1) \mathrm{PV}$ Array}

To obtain the input voltage of $110 \mathrm{~V}_{\mathrm{dc}}$ for the inverter, six panels are connected in series and the characterization is done by connecting a rheostat as the load. The V-I and V-P characteristics of PV are shown Figure 14 (a) and 14 (b). The readings are taken for three different environmental conditions. The dotted line in the Figure. 14 (a) and 14 (b) represents the graph obtained for the practical values and the continuous line represents the graph obtained after using proper curve fitting.

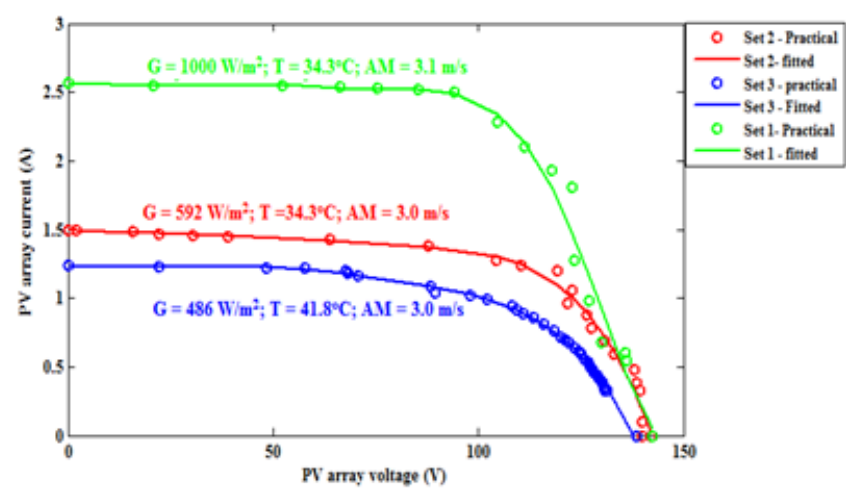

(a)

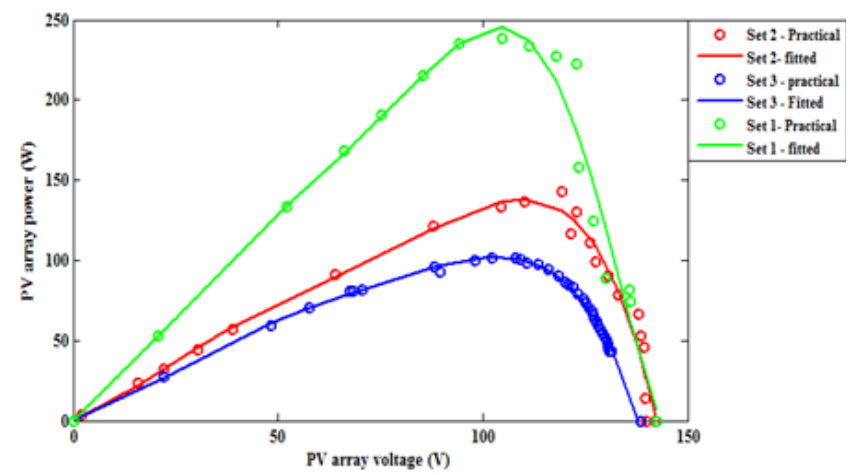

(b)

Figure 14. Characterization of PV (a) V-I characteristics, (b) V-P characteristics.

\subsection{Prototype of HBZVR Topology}

The prototype of HBZVR transformer-less topology is developed, as this topology is found to be the best in terms of both leakages current and THD (\%) among all the other three topologies discussed. Figure 15 shows the experimental setup for generation of switching pulse for HBZVR topology using FPGA processor. The driver circuit is developed using IC MCT2E for protection. The switching pattern generated for HBZVR topology is shown in Figure 16.

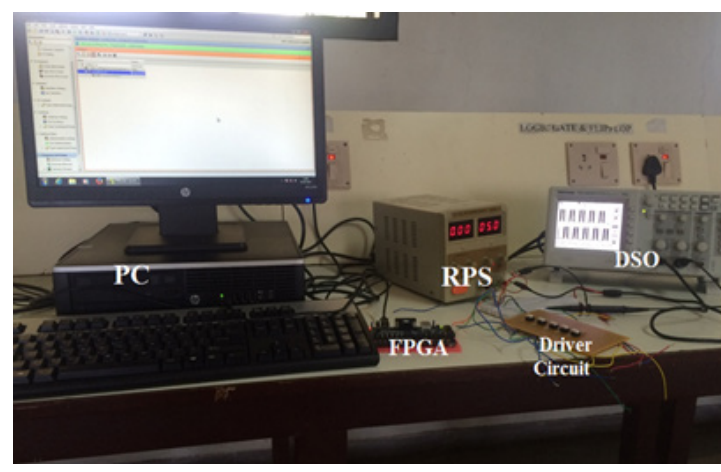

Figure 15. Experimental setup for generation of switching pulse. 


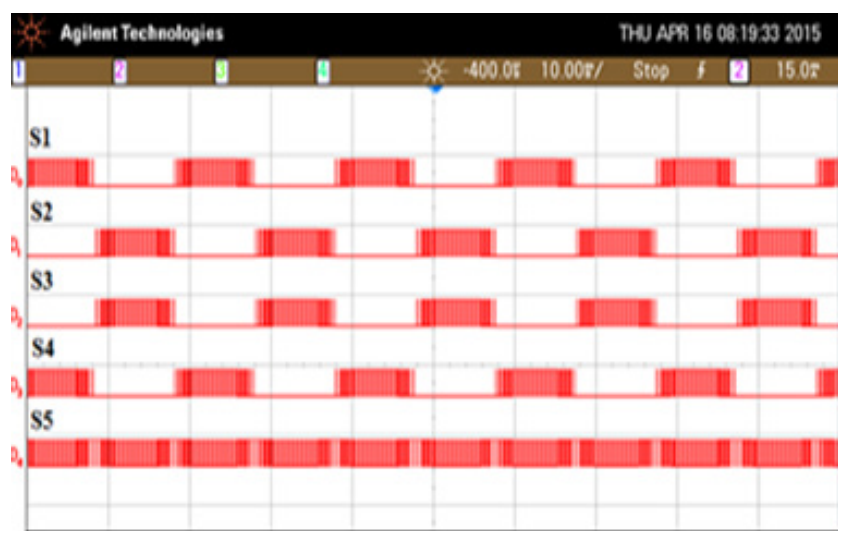

Figure 16. Switching pulse pattern for HBZVR topology.

The experimental setup for HBZVR topology is shown in Figure 17 and the results of HBZVR topology including inverter voltage before filter, inverter voltage after filter and load current is shown in Figure 18 and the leakage current is shown in Figure 19. A step down transformer is used to convert $230 \mathrm{~V}_{\mathrm{ac}}$ to $55 \mathrm{~V}_{\mathrm{ac}}$, which is then rectified using diode bridge rectifier and is given as input for the inverter.

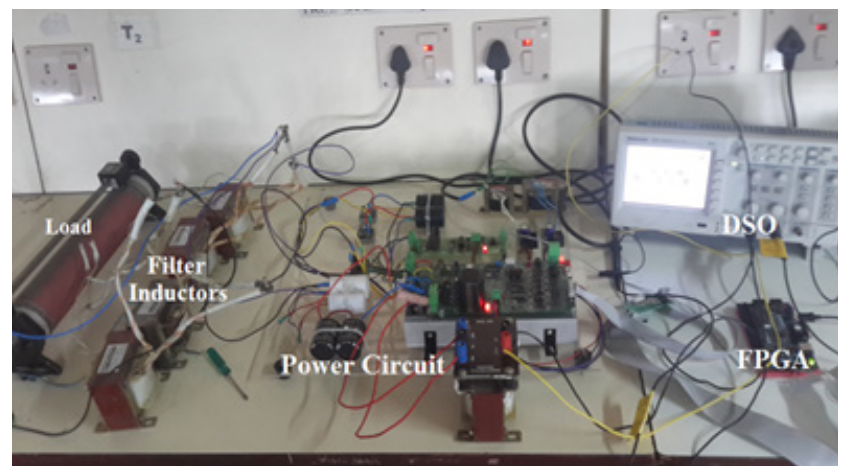

Figure 17. Experimental setup for HBZVR topology.

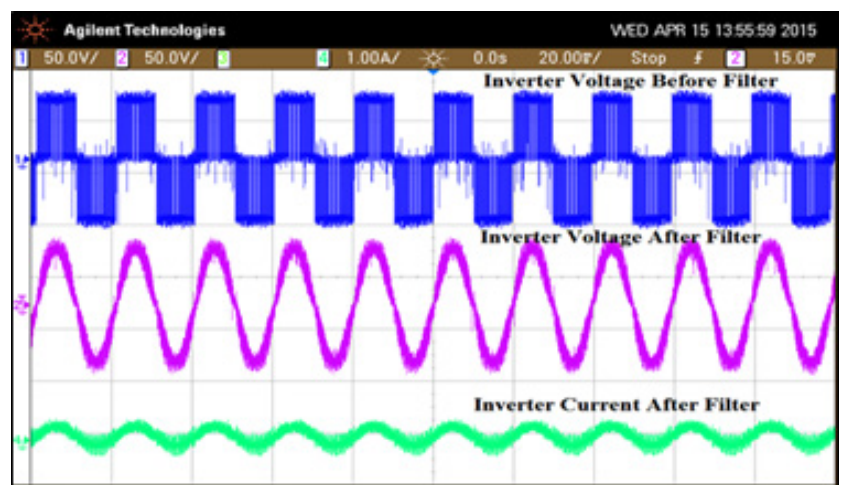

Figure 18. Experimental results of HBZVR topology.

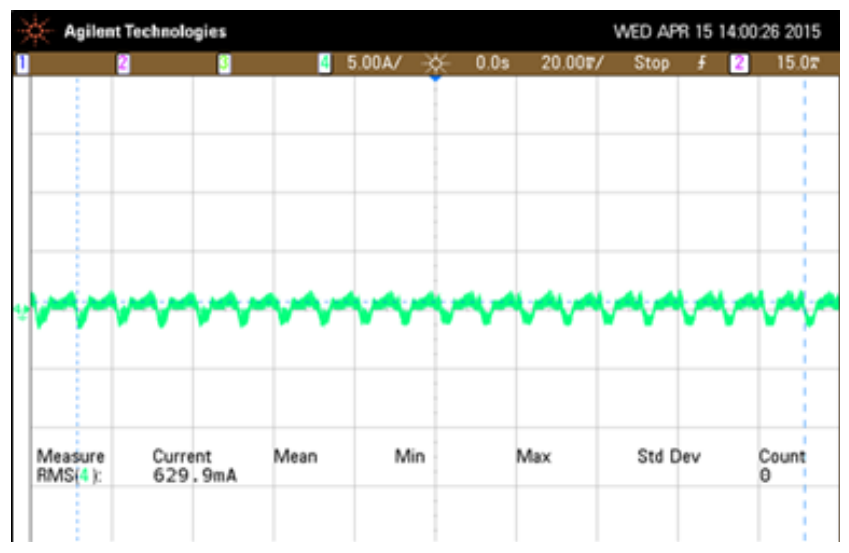

Figure 19. Leakage current of HBZVR topology.

The leakage current is measured as $629.9 \mathrm{~mA}$ for HBZVR topology.

\section{Conclusions}

In this paper, a comparative analysis of different transformer-less topology like $\mathrm{H} 5, \mathrm{H} 6, \mathrm{oH} 5$ and HBZVR topology is made in terms of leakage current and THD (\%). The leakage current mainly depends on Common Mode Voltage (CMV) and the condition to eliminate leakage current is to maintain CMV constant. The CMV in HBZVR topology is nearly constant and so the leakage current is almost eliminated. Also, since ac-decoupling is used in HBZVR topology, the THD (\%) is less in this topology comparatively. So considering both leakage current and THD (\%), HBZVR topology is found to be the best. The prototype of HBZVR topology is also developed and the experimental results are validated.

\section{References}

1. Suan FTK, Rahim NA, Ping HW. Modeling, analysis and control of various types of transformerless grid connected PV inverters. Proceedings of IEEE Clean Energy Technology, Malaysia; 2011 Jun. p. 51-6.

2. Li Q, Wolfs P. A review of the single phase photovoltaic module integrated converter topologies with three different dc link configurations. IEEE Transactions on Power Electronics. 2008 May; 23(3):1320-33. Crossref.

3. Gonzalez R, Lopez J, Sanchis P, Marroyo L. Transformerless inverter for single-phase photovoltaic systems. IEEE Transactions on Power Electronics. 2007 Mar, 22(2):693-7. Crossref. 
4. Kerekes T, Teodorescu R, Liserre M, Klumpner C, Sumner M. Evaluation of three-phase transformerless photovoltaic inverter topologies. IEEE Transactions on Power Electronics. 2009 Aug; 24(9):2202-11. Crossref.

5. Rahim NA, Chaniago K, Selvaraj J. Single-phase sevenlevel grid connected inverter for photovoltaic system. IEEE Transactions on Industrial Electronics. 2011 Jun; 58(6):2435-43. Crossref.

6. Calais M, Myrzik M, Spooner T, Agelidis VG. Inverters for single phase grid connected photovoltaic system - An overview. IEEE Power Electronics Specialist Conference, Birmingham, United Kingdom; 2011 Aug; 4:1995-2000.

7. Patrao I, Figureueres E, González-Espin F, Garcera G. Transformerless topologies for grid connected single-phase photovoltaic inverters. Renewable and Sustainable Energy Reviews. 2011 Sep; 15(7):3423-31. Crossref.

8. Patel H, Agarwal VA. Single-stage single-phase transformer-less doubly grounded grid-connected PV interface. IEEE Transactions on Energy Conversion. 2009 Mar; 24(1):93-101. Crossref.

9. Villalva MG, Gazoli JR, Filho ER. Comprehensive approach to modeling and simulation of photovoltaic arrays. IEEE Transactions on Power Electronics. 2009 May; 24(5):1198-208. Crossref.

10. Walker G. Evaluating MPPT converter topologies using a MATLAB PV model. Australian Journal of Electrical and Electronics Engineering. 2014 Oct; 21(1):49-55.

11. Zhang L, Sun K, Feng L, Wu H, Xing Y. A family of neutral point clamped full-bridge topologies for transformerless photovoltaic grid-tied inverters. IEEE Transactions on Power Electronics. 2013 Feb; 28(2):730-9. Crossref.

12. Araujo SV, Zacharias P, Mallwithz R. Highly efficient single phase transformerless inverters for grid-connected photovoltaic systems. IEEE Transactions on Industrial Electronics. 2010 Sep; 57(9):3118-28. Crossref.

13. Yang B, Li W, Gu Y, Cui W, He X. Improved transformerless inverter with common-mode leakage current elimination for a photovoltaic grid-connected power system. IEEE Transactions on Power Electronics. 2012 Feb; 27(2):752-62. Crossref.

14. Gubia E, Sanchis P, Ursua A, Lopez J, Marroyo L. Ground currents in single-phase transformerless photovoltaic systems. Progress in Photovoltaic Applications. 2007 Nov; 15(7):629-50. Crossref.
15. Xiao HF, Lan K, Zhang L. A quasi-unipolar SPWM fullbridge transformerless PV grid-connected inverter with constant common-mode voltage. IEEE Transactions on Power Electronics. 2015 Jun; 30(6):3122-32. Crossref.

16. Sekar RAR, Prasad DA. Improved transformerless inverter for PV grid connected power system by using ISPWM technique. International Journal of Engineering Trends and Technology. 2013 Apr; 4(5):1512-17.

17. Islam M, Hasan M, Akter P, Rahman MDM. A new transformerless inverter for grid connected photovoltaic system with low leakage current. International Conference on Electrical Information and Communication Technology (EICT), Bangladesh; 2013 Feb. p. 1-6. PMCid:PMC3794383

18. Yu W, Lai JS, Quian H, Hutchens C. High-efficiency MOSFET inverter with H6-type conFigureuration for photovoltaic non-isolated AC-module applications. IEEE Transactions on Power Electronics. 2011 Apr; 26(4):1253-60. Crossref.

19. Cavalcanti MC, De Oliveira KC, De Farias AM, Neves FAS, Azevedo GMS, Camboim FC. Modulation techniques to eliminate leakage currents in transformerless three-phase photovoltaic systems. IEEE Transactions on Industrial Electronics. 2010 Apr; 57(4):1360-8. Crossref.

20. Jasmine B, Anjumol CS. Leakage current elimination in single phase transformer less grid connected power systems. International Journal of Innovative Research in Electrical, Electronics, Instrumentation and Control Engineering. 2014 Mar; 2(3):1266-71.

21. Vazquez G, Kerekes T, Rolan A, Aguilar D, Luna A, Azevedo G. Losses and CMV evaluation in transformerless grid-connected PV topologies. Proceedings of the IEEE International Symposium on Industrial Electronics (ISIE 2009), Seoul; 2009 Jul. p. 544-8. Crossref.

22. Kerekes T, Teodorescu R, Rodríguez P, Vázquez G, Aldabas E. A new high-efficiency single-phase transformerless PV inverter topology. IEEE Transactions on Industrial Electronics. 2011 Jan; 58(1):184-91. Crossref.

23. Cha W-J, Kim K-T, Cho Y-W, Lee S-H, Kwon B-H. Evaluation and analysis of transformerless photovoltaic inverter topology for efficiency improvement and reduction of leakage current. IET Power Electronics. 2015 Feb; 8(2):255-67. Crossref.

24. Xiao H, Xie S, Chen Y, Huang R. An optimized transformerless photovoltaic grid-connected inverter. IEEE Transactions on Industrial Electronics. 2011 May; 58(5):1887-95. Crossref. 